\title{
A ESCOLA NA SOCIEDADE CONTEMPORÂNEA: UMA VIA NA CONTRAMÃO DA SAÚDE?
}

Izaldina Queiroz Simas'; José Osman dos Santos²

Mestranda do programa de pós-graduação em Educação Profissional e Tecnológica - PROFETP - Instituto Federal de Sergipe, Aracaju, Sergipe, Brasil.

2 Professor Doutor do programa de pós-graduação em Educação Profissional e Tecnológica - PROFETP - Instituto Federal de Sergipe, Campus Lagarto, Lagarto, Sergipe, Brasil. iqsufba@gmail.com

Recebido em: 15/08/2021 - Aprovado em: 15/09/2021 - Publicado em: 30/09/2021 DOI: 10.18677/EnciBio_2021C1

trabalho licenciado sob licença Creative Commons Attribution-NonCommercial-NoDerivatives 4.0 International License.

\section{RESUMO}

Este artigo visa contribuir para a discussão da saúde escolar. A reflexão é necessária principalmente pela histórica relação da escola com a sociedade, especialmente para os jovens oriundos da classe trabalhadora que necessitam de uma formação para inclusão imediata no mercado de trabalho e buscam na escola uma formação que possibilite esta concretização. Embora a abordagem se refira às scolas de forma ampla, a discussão gira em torno dos Institutos Federais de Educação Profissional e Tecnológica, seu papel na formação e cuidado dos educandos, e consequentemente na permanência e no êxito. A escola é estritamente vinculada às formas de produção da sociedade, o que gera um paradoxo quando se tentar buscar nesta escola um caminho para a transformação social, a autonomia dos sujeitos, o desenvolvimento pessoal. À escola cabe a função precípua de educar, mas a educação escolar engloba toda a complexidade da construção humana, e neste caminho a manutenção e a proteção da saúde. Saúde e educação devem caminhar juntas na escola, mas a escola assim concebe efetivamente, através de mecanismos concretos? A discussão gira em torno deste questionamento e a explanação se deu através de estudo bibliográfico e documental. Por fim, foi possível apreender que a escola não possui um plano ou política de saúde escolar institucionalizado, carecendo da criação desta política/plano e para tal foram apresentados alguns elementos e etapas importantes, além de iniciativas necessárias para esta finalidade, considerando, sobretudo, a realidade específica.

PALAVRAS-CHAVE: Escola. Sociedade. Saúde. 


\title{
SCHOOL IN CONTEMPORARY SOCIETY: A ROUTE TO HEALTH AGAINST (?)
}

\begin{abstract}
This article aims to contribute to the discussion of school health. This reflection is mainly necessary due to the historical relationship between the school and society, especially for young people from the working class who need training for immediate inclusion in the labor market and who seek training in school to enable this achievement. Although the approach refers to schools in a broad way, the discussion revolves around the Federal Institutes of Professional and Technological Education and their role in the training and care of students, and consequently in their permanence and success. The school is strictly linked to society's forms of production, which creates a paradox when trying to seek in this school a path to social transformation, the autonomy of subjects, and the personal development. The school has the primary function of educating, but school education encompasses all the complexity of human construction, and in this way the maintenance and protection of health. Health and education must go hand in hand at school, but does the school effectively conceive this way, through concrete mechanisms? The discussion revolves around this questioning and the explanation took place through a bibliographic and documentary study. Finally, it was possible to apprehend that the school does not have an institutionalized school health plan or policy, lacking the creation of this policy/plan and for this, some important elements and steps were presented, in addition to the initiatives necessary for this purpose, considering, above all, the specific reality.
\end{abstract}

KEYWORDS: School. Society. Health.

\section{INTRODUÇÃO}

A educação é fundamental para a formação dos sujeitos, para o desenvolvimento pessoal e social, para a conscientização política e cidadã. Para a concretização desta finalidade é primordial um processo pedagógico saudável, por isto, esta abordagem parte da necessidade da discussão da saúde na escola como elemento primordial para a formação integral, a permanência e o êxito. Da saúde e educação como direitos sociais (BRASIL,1988) e, neste sentido, da escola como transformadora da sociedade através da formação de qualidade.

O tema será abordado considerando a saúde e a educação como elementos indissociáveis, partindo de um conceito ampliado de saúde, sendo esta definida como um estado de completo bem estar físico, mental e social e não consistindo somente da ausência de doença ou enfermidade (OMS, 1978).

Embora o conceito de saúde leve a um todo que interage entre si (físico, mental, social) o foco desta explanação é principalmente no bem estar psíquico por ser uma forma de menos evidência e percepção, pois as manifestações não se dão de forma tão evidente quanto uma alteração orgânica, podendo gerar agravos à saúde como um todo (PERUZZO et al., 2017).

O objeto de análise é o Ensino Médio Integrado - EMI à Educação Profissional e Tecnológica - EPT, ofertado pelo Instituto Federal. Assim serão consideradas as especificidades do processo de ensino-aprendizagem desta modalidade; o aspecto das relações econômicas, históricas, sociais e pedagógicas do sujeito envolvido; e os desafios neles contidos. Sobre estes desafios, é possível perceber que são manifestados na contemporaneidade de diversas formas, presentes nas diferentes formas de produção da vida: 


\begin{abstract}
"É exigido das pessoas, qualificação, trabalho, têm que bater metas, alcançar objetivos, estudarem para ser alguém, para ter dinheiro e com isso dificilmente conseguem encontrar momentos em que possam se relacionar mais, se coletivizar mais para poder pensar juntos e criar formas mais potentes de vida. $E$ isso se coloca em todos os espaços, trabalho, casa, rua, escola" (NEGREIROS; SOUZA, 2017, p 168).
\end{abstract}

Atender a estas exigências, sobretudo para os jovens escolares da classe trabalhadora, que por definição é a classe que vive do trabalho (ANTUNES, 2003), torna-se uma grande batalha e pode se configurar em um potencializador de agravos, pois essas exigências são refletidas na escola, em decorrência da reprodução da lógica econômica no processo pedagógico (BERTRAND, 2001).

Nesse sentido, a abordagem parte da reflexão sobre "a via da escola" e da educação neste processo de proporcionar um processo formativo mais saudável, no sentido de repensar sobre seu papel para o cuidado com a saúde dos escolares, para que a formação escolar não se torne um fator de risco para a saúde como um todo (GRANER; CERQUEIRA, 2019).

Em atenção a este ponto, um estudo realizado pelo Departamento de Neurologia e Psiquiatria da Faculdade de Medicina de Botucatu, da Universidade Estadual Paulista Júlio de Mesquita Filho, intitulado "Revisão integrativa: sofrimento psíquico em estudantes universitários e fatores associados" reuniu dezenas de estudos sobre os fatores de risco e proteção para o sofrimento psíquico em estudantes universitários (GRANER; CERQUEIRA, 2019).

$O$ estudo agrupou os fatores associados ao sofrimento psíquico em seis categorias: Sociodemográficas - idade, sexo, arranjo de moradia, dados familiares, renda e religiosidade; Saúde - condições e percepções sobre a sua saúde, estilo de vida e histórico de tratamentos psicológico/ou psiquiátrico; Relacionais - percepção sobre relacionamentos sociais/apoio social; Acadêmicas - características do curso, percepções sobre o curso, ambiente educacional e desempenho acadêmico; Psicológicas - traços de personalidade, estratégias de coping e resiliência; e Sociais/Violência - discriminação e violência social (GRANER; CERQUEIRA, 2019)

Foi observado que as variáveis mais frequentes como fatores de risco para sofrimento psíquico foram as classificadas na categoria "Acadêmicas" (24 estudos), chamando-se a atenção para a subcategoria série do curso (três referindo-se às primeiras e dois às últimas séries), ter pensado em abandonar o curso, excesso de horas de estudo ou dificuldade para conciliar estudo, lazer/descanso em dois estudos, assim como apontar o curso como fonte de estresse/tensão, ter expectativas ruins em relação ao futuro profissional, insatisfação com o curso/ter pouco interesse pelo mesmo e sentir desconforto durante as atividades (GRANER; CERQUEIRA, 2019).

Pesquisas também destacam a desigualdade nas ações de promoção à saúde nas diversas regiões do País e redes de ensino (HORTA et al., 2017). Diante deste cenário torna-se crucial o cuidado e o acolhimento pela escola através da promoção, prevenção e atenção à saúde com ações e estratégias concretas para este fim.

Para Valadão (2004, p. 10), a "expressão 'saúde na escola' é utilizada para designar o campo que compreende concepções, diretrizes, programas, projetos e ações relacionadas à saúde que acontecem no cenário da escola, sejam de natureza educativa, preventiva ou assistencial". A autora defende ainda que a "promoção da saúde na escola corresponde a uma visão e conjunto de estratégias 
que têm como objetivo produzir repercussões positivas sobre a qualidade de vida e os determinantes da saúde dos membros da comunidade escolar".

A partir destas perspectivas, este artigo objetivou, através de estudo bibliográfico e documental sobre o tema, discutir a relação da educação e da escola na formação atual estabelecendo um contraponto com a sociedade contemporânea e a evasão escolar, ainda que esta não seja o foco da discussão, mas como possível consequência do adoecimento no percurso escolar a ser analisada como elemento de atenção pela instituição educativa em realce, visando, sobretudo não esgotar a temática, mas contribuir para a discussão, propondo possíveis iniciativas.

As iniciativas propostas têm a pretensão de apresentar elementos e caminhos para a construção de uma política de saúde escolar, efetiva e permanente, que colabore para as práticas de hábitos saudáveis e de cidadania no ambiente escolar, colaborando, em adição, para a redução de possíveis adoecimentos no percurso formativo diante do cenário apresentado.

\section{A EDUCAÇÃO E A ESCOLA NA SOCIEDADE CONTEMPORÂNEA: A VINCULAÇÃO PARA O ADOECER?}

Que a educação é fonte para o desenvolvimento humano é inegável. Que é direito fundamental tão quanto. Não há dissenso nestas perspectivas. A Constituição Federal de 1988, assim define no art. 205: "A educação, direito de todos e dever do Estado e da família, será promovida e incentivada com a colaboração da sociedade, visando ao pleno desenvolvimento da pessoa, seu preparo para o exercício da cidadania e sua qualificação para o trabalho" (BRASIL, 1988).

A referida educação é a fornecida através de uma instituição, a escola. E esta educação é [...] "uma fração do modo de vida dos grupos sociais que a criam e recriam, entre tantas outras invenções de sua cultura, em sua sociedade [...]" (BRANDÃO, 2006, p.10 citado por MARTINS; WINGERT, 2017), o que permite afirmar que a educação escolar está vinculada aos modos de produção da vida social, política e econômica.

Esta vinculação, contudo, segundo Bertrand (2001), denota um problema. O teórico enfatiza que "o problema da escola é a sua relação com a sociedade: a escola é um instrumento cultural de seleção e de reprodução a serviço das classes dominantes" (BERTRAND, 2001, p. 173). Apesar da perspectiva apontada pelo teórico, é possível pensar numa direção reversa, pois:

[...] a educação é um fenômeno complexo, porque histórico. Ou seja, é produto do trabalho de seres humanos e, como tal, responde aos desafios que diferentes contextos políticos e sociais lhe colocam. A educação retrata e reproduz a sociedade; mas também projeta a sociedade que se quer [...] (PIMENTA, 2008 citado por MARTINS; WINGERT, 2017, p. 38).

Partindo do paradoxo apontado por estes autores ainda é possível vislumbrar na escola as possibilidades de mudança. Além disso, Araújo e Silva (2017) argumentam, em outras palavras, que apesar de a educação institucional fornecida pela escola servir à lógica societal, ela ainda é o espaço mais propício para o crescimento humano e social:

Ainda que a escola não possa ser considerada o único lócus em que a formação humana aconteça, ela deve ser vista como um espaço privilegiado, uma relevante oportunidade na trajetória de estudantes de diferentes origens sociais, uma alternativa para se construir valores que terão impacto positivo na constituição de uma sociedade mais justa e democrática (ARAÚJO; SILVA, 2017, p.8). 
Se assim é concebida, a garantia do sucesso acadêmico, especialmente desta modalidade de ensino, depende da conjugação de fatores que perpassam desde as condições formativas proporcionadas até o modo singular como os indivíduos vivenciam as experiências atuais da formação (NEGREIROS; SOUZA, 2017).

Por este argumento, a educação escolar para além da função precípua de fornecer os processos de ensino e aprendizagem, precisa fazê-lo de forma salutar. Assim, falar de saúde na escola, que abarcam práticas que levem à promoção e a prevenção da saúde do escolar (VALADÂO, 2004) é uma necessidade, especialmente na escola pública brasileira, diante da vinculação histórica, de constantes transformações econômicas e sócio-políticas (ANTUNES, 2003). Apontadas por Antunes (2003), essas transformações são provenientes da crise do capitalismo dos anos 70 e posterior reestruturação nas décadas seguintes, com introdução dos modos de produção taylorista/fordista e, por fim, o toyotista com a acumulação flexível:

A crise experimentada pelo capital, bem como suas respostas, das quais o neoliberalismo e a reestruturação produtiva da era da acumulação flexível são expressão, têm acarretado, entre tantas consequências, profundas mutações no interior do mundo do trabalho. Dentre elas pode-se inicialmente mencionar o enorme desemprego estrutural, um crescente contingente de trabalhadores em condições precarizadas, além de uma degradação que se amplia, na relação metabólica entre homem e natureza conduzida pela lógica societal voltada prioritariamente para a produção de mercadorias e para a valorização do capital. (ANTUNES, 2003, p.15).

Sobre este modelo de produção, Antunes e Pinto (2017), destacam que:

Em seus traços básicos, o toyotismo estabelece uma produção mais diretamente vinculada à demanda, diferenciando-se com frequência da produção em série e de massa do taylorismo-fordismo. É um sistema que se estrutura no trabalho em equipe, rompendo com o caráter parcelar típico do fordismo, baseando-se num processo flexivo onde 0 trabalhador opera simultaneamente várias máquinas. (p. 64).

As alterações no mundo do trabalho apresentadas pelos estudiosos são refletidas no sistema educacional, visto que é preciso "formar" o trabalhador - nesse contexto também flexível - para atender aos imperativos da acumulação (ANTUNES, 2003). Para este trabalhador, a educação tem a finalidade mercadológica. A formação ocorre então para o imediatismo do mercado, no entanto, de forma dual, que se caracteriza pela dissociação entre teoria e prática ou trabalho manual versus trabalho intelectual (MOURA, 2007).

Neste cenário, as perspectivas de mudança de vida através da educação escolar e do trabalho em seu sentido ontológico podem ser frustradas diante das exigências do capital, gerando ainda mais precarizações, desigualdades, competividade, violências e não menos importante na contemporaneidade, adoecimentos em sentido amplo (CHARLOT, 2014). Para este autor:

Há aí uma contradição fundamental da sociedade atual. Essa lógica da concorrência causa, também, um sofrimento geral, o dos alunos, dos professores, dos pais. Talvez esse sofrimento seja, além da sua dimensão subjetiva e social, um sintoma de ferida antropológica: quando aprender, ou seja, participar da aventura humana, passa a se adquirir um capital que possibilita dominar outros seres humanos; é a própria espécie humana que sofre (CHARLOT, 2014, p. 83). 
Corroborando com este pensamento Silva e Silva (2018) salientam que "o adoecimento deve ser apreendido como um fenômeno ligado à sociedade moderna. Além de ser um dos elementos constitutivos para a compreensão do pertencimento à classe trabalhadora, cada vez mais impactada pelas mudanças da sociabilidade capitalista" (p. 4). Em inferência ao que argumenta Han (2015), os agravos à saúde são ainda mais dimensionados porque há uma exigência e cobrança pessoais. Propaga-se a ideia de que é preciso ser, fazer e estar sempre melhor em tudo e com tudo, e segue-se incentivando esse jogo nas jovens gerações que se sucedem, no trabalho, na escola. E a consequência é que "o excesso da elevação do desempenho leva a um infarto da alma" (HAN, 2015, p. 37). O filósofo argumenta ainda que:

\begin{abstract}
O excesso de trabalho e desempenho agudiza-se numa autoexploração. Essa é mais eficiente que uma exploração do outro, pois caminha de mãos dadas com o sentimento de liberdade. $O$ explorador é ao mesmo tempo o explorado. Agressor e vítima não podem mais ser distinguidos. Essa autorreferencialidade gera uma liberdade paradoxal que, em virtude das estruturas coercitivas que the são inerentes, se transforma em violência. Os adoecimentos psíquicos da sociedade de desempenho são precisamente as manifestações patológicas dessa liberdade paradoxal (HAN, 2015, p. 16 e 17).
\end{abstract}

Diante do exposto e da "[...] compreensão de uma função da escola que não seja apenas acadêmica, mas também social" (DEL PRETTE; DEL PRETTE, 1998, p. 110 citados por NEGREIROS; SOUZA, 2017), é imperioso refletir se as escolas buscam cuidar dos seus jovens para que reduzam os efeitos das novas exigências da sociedade moderna para a saúde, principalmente psíquica; se é possível à escola atenuar esses impactos no processo formativo e conseqüentemente, inserir profissionais integrais e minimamente saudáveis no mercado de trabalho

\title{
DO "LADO DE CÁ": A FORMAÇÃO NA REDE FEDERAL E O CUIDADO COM A SAÚDE DOS ESCOLARES
}

Na discussão anterior foi possível apreender que a educação é historicamente relacionada aos modelos econômicos e políticos vigentes, logo a Educação Profissional e Tecnologia ofertada pelos então atuais Institutos Federais não é excluída deste paradigma, historicamente marcada pela dualidade entre educação básica e propedêutica (MOURA, 2007). Principalmente porque a educação profissional técnica (básica) está intrinsecamente associada ao mercado de trabalho, o que torna a formação ainda mais desafiadora para os sujeitos que buscam a escola para a mudança da realidade (MOURA, 2007).

Antes de adentrar à reflexão aberta no capítulo anterior sobre a função da escola e seu papel na atenuação da realidade destacada, é importante conhecer brevemente a história do surgimento dos institutos federais, instituições escolares tão necessárias para os jovens da classe trabalhadora na sociedade brasileira contemporânea (ARAÚJO; SILVA, 2017).

Até chegar ao que se conhece hoje como Instituto Federal de Educação Profissional e Tecnológica, essas instituições passaram por trajetória de pouco mais de um século e se destinam historicamente à educação dos jovens da classe trabalhadora. O marco inicial da educação profissional foi o ano de $1909 \mathrm{com}$ a criação pelo Estado das Escolas de Aprendizes e Artífices; a partir daí, com o avanço da industrialização essas escolas e a educação ofertada por elas foram "adaptadas" de acordo com a necessidade socioeconômica (RAMOS, 2014). 
Logo, a partir da década de 1930 houve expansão da industrialização no País, com isso necessidade de mão de obra, surgindo os Liceus Industriais. $\mathrm{Na}$ década seguinte, precisamente no ano de 1942, tomam lugar as Escolas técnicas industriais. $\mathrm{Na}$ década de 70 houve aumento na oferta de cursos e vagas nas escolas técnicas. Esta década é marcada por acontecimentos políticos e sociais, como a ditadura militar, expansão da industrialização, alterações nos modos de produção, e novamente a necessidade de formação em massa para atender aos imperativos do mercado (RAMOS, 2014).

A partir de então houve ampliação física - principalmente para as cidades do interior - e maior democratização das vagas nas escolas de formação profissional com maior destaque para a primeira década deste século, período em que houve a transformação das escolas em Institutos Federais através da lei no 11.892 de 2008, com autonomia administrativa e financeira. A regulamentação e estruturação da educação profissional e tecnológica na atual LDB - Lei de Diretrizes e Base da Educação (1996) foi um importante passo. Bem como a inclusão na normativa da possibilidade de articulação do ensino médio integrado à educação profissional e tecnológica, o que possibilita a formação integral e completa dos educandos (RAMOS, 2014).

Contudo, além da necessidade de democratizar a oferta, de atender às funções de desenvolvimento local e regional através da interiorização, é necessário também um olhar atento à dinâmica interna em que ocorre essa formação, o contexto que ela está inserida e os impactos na formação, na vida e na saúde dos sujeitos. E essencial considerar a sociedade contemporânea e suas contradições nessa dinâmica e, ademais, a complexidade da realidade sócio histórica dos sujeitos para que não seja instalado um paradoxo de no lugar de cumprir uma função social, a escola venha a contribuir para o agravamento do quadro de mazelas, pois de acordo com Araújo e Silva (2017):

O Ensino Médio Integrado é uma forma de resistência e de transformação. É de resistência a um modelo de escola que opera pela lógica da exclusão, pela culpabilização individual do fracasso em relação ao estudante; é de resistência a um modelo de educação abstrato e compartimentalizado, o qual ignora o mundo juvenil. Por outro lado, sendo um projeto que visa à transformação individual e social, esse projeto tem de possuir uma concepção de educação contextualizada às aspirações do mundo juvenil, às suas vivências, às suas trajetórias e às suas histórias. Sendo assim, é um projeto de formação integral comprometido com o desenvolvimento social, cultural e econômico do país (p. 12).

Entretanto, há barreiras para o sucesso do citado comprometimento na formatação de sociedade imposta, pois:

"na constituição histórica da escola, verificamos seu papel reprodutor, materializado nos tempos e espaços fixos e rígidos; na divisão da teoria e da prática; nos currículos fechados em conteúdos que se distanciam da vida e dos problemas advindos da complexidade do cotidiano; no aligeiramento da formação para constituir um sujeito produtivo e consumidor; na subsunção da dimensão humana pelo conteúdo curricular que visa preparar mecanicamente o educando para servir um tal futuro do trabalho; e na consigna do amoldamento do sujeito para adequar-se, sem crítica, às correias da engrenagem que sustenta o funcionamento da sociedade (VARANI et al., 2019, p. 7).

O argumento das autoras conversa com a nova sociabilidade (ANTUNES, 2003) do sistema, que impõe aos jovens que logo tenha uma formação e ocupação, que e sejam inseridos no mercado de trabalho, e que se adaptem às outras 
ocupações, se for o caso, exigindo novos conhecimentos e níveis de formação. Neste quesito é que encontram-se as dificuldades tanto para a execução como para - sucesso dessa proposta de ensino, como uma trajetória saudável capaz de colaborar para a reversão deste novo formato social. Justamente porque Kuenzer (2020), ao refletir sobre Sistema educacional e a formação de trabalhadores caracteriza a formação profissional como precarizada, reforçando o entendimento de que na prática há principalmente a soma de currículos e cargas horárias, contrariando a finalidade de formação ampla e integral dos sujeitos.

Em adição, a escola em realce, com a finalidade de uma formação integral e emancipadora, tem uma modalidade de ensino peculiar que gera uma sobrecarga de atividades e conteúdos que podem impactar na permanência, aumentando os números da evasão escolar, conforme evidenciado pelo estudo de caso realizado pelo Instituto Federal de Goiás (IFG), Campus Uruaçu (ALMEIDA, 2018).

O estudo apresentou os principais desafios para a conclusão do Ensino Médio Integrado no IFG. Teve como investigados os discentes concluintes de três cursos, os pais e docentes. A partir dos dados, concluiu-se que: segundo os discentes, os principais "problemas ou dificuldades" enfrentados durante a realização do curso no IFG, foram: a carga horária extensa do curso (muitas disciplinas no ano letivo); o excesso de trabalhos e atividades, pelo fato do curso ser em tempo integral e eles permanecerem o dia todo na Instituição; e a adaptação com o ritmo da instituição (ALMEIDA, 2018).

De acordo com o estudo, os pais e docentes que responderam ao questionário convergiram para a mesma ideia referente à estrutura curricular e excesso de trabalhos e atividades do curso. Por esse aspecto, a autora argumenta que as diretrizes propostas para educação em tempo integral presente na Constituição de 1988, no Estatuto da Criança e do Adolescente (ECA) e na Lei de Diretrizes e Bases (LDB) visam o aumento da jornada escolar como uma maneira de democratizar o acesso à cultura e de diminuir as diferenças sociais, no entanto, na prática a estrutura produz um excesso que impossibilita o aluno de participar de outras atividades complementares e essenciais à formação como "aquelas relativas ao tripé ensino, pesquisa e extensão, como as monitorias, reforços, recuperações, projetos de ensino, de iniciação científica e atividades esportivas e culturais" (ALMEIDA, 2018, p. 10).

Além do risco de gerar uma formação precarizada, há a possibilidade de tonar-se um fator de risco para a saúde psíquica, pois no aspecto pedagógico há integração de conteúdos e disciplina (teoria versus prática), visando à formação básica com a profissionalização. Este somatório pode desencadear uma sobrecarga, como enfatizado pelo estudo, causando angústia e desmotivação, além da sensação de fracasso por não conseguir cumprir a demanda (SOUZA; TEIXEIRA, 2016).

O questionamento que surge desse contexto é se essa escola diante deste cenário complexo possui mecanismos concretos e permanentes de enfrentamento de possíveis adoecimentos causados pelo processo formativo para além da configuração do setor de assistência estudantil formado por profissionais que atuam de forma específica e pontual, sobretudo de forma assistencial ou atendimentos emergenciais (ALMEIDA, 2018).

As próprias normativas da instituição, como o Plano de Desenvolvimento Institucional (PDI), o Projeto Político Pedagógico Institucional (PPPI) e os Projetos Pedagógicos dos Cursos (PPC) respondem. Em consulta aos normativos foi possível identificar que as orientações e princípios nestes explicitados são concernentes ao 
âmbito majoritariamente pedagógico e de processos neste sentido, sendo o cuidado com o ambiente escolar e a saúde dos educandos desfocados (BRASIL, 2014a).

Em breves momentos em que trata da saúde dos escolares o Plano De Desenvolvimento Institucional (PDI 2014-2019) do Instituto Federal de Sergipe o faz de forma assistencial e curativa. No capítulo ligado à Diretoria de Assistência Estudantil quando aborda os Objetivos Estratégicos e Metas, a meta para a saúde se resume a: "Implantação de salas para atendimento de saúde, plantão médico e primeiros socorros, em todos os campi" (p. 54). Ainda neste documento (p. 390) a saúde é tratada como uma das ações de estímulo à permanência, nesse caso, dentre outros estímulos através de bolsas, a saúde possui a bolsa saúde, sem especificar os parâmetros e ações concretas para o cuidado com a saúde (BRASIL, 2014a). Percebe-se que há uma carência de medidas claras e institucionalizadas para a promoção, prevenção e proteção da saúde. Ratificando esta alegação, de acordo com Machado et al. (2019):

"no âmbito dos IFs é disponibilizada assistência à saúde dos discentes para viabilizar um ambiente favorável às habilidades e capacidades necessárias à formação pedagógica e cidadã. Todavia, não há formalização de uma política de saúde, sendo os setores de saúde balizados pela política de assistência estudantil característica dos IFs. Portanto, não há um planejamento estratégico próprio de serviços de saúde em essência" (p. 4041).

Esta falta vai de encontro às finalidades da própria formação integral, que pelo conceito denota uma formação completa, na qual deve incluir condições e estratégias para proteção da saúde. Ademais, a partir dos dados apresentados por Machado et al. (2019), é possível inferir que a ausência de uma política efetiva de saúde com ações permanentes e concretas para a saúde dos educandos, somado às dificuldades para conclusão inerentes ao próprio curso podem ser elementos contributivos para o insucesso escolar, manifestado através da evasão, por exemplo. $E$ ainda que esta discussão não tenha a evasão como foco, cabe a reflexão de sua relação com a saúde do escolar diante deste quadro.

Uma análise do Documento Orientador para a Superação da Evasão e Retenção na Rede Federal de Educação Profissional, Científica e Tecnológica criado pela Secretaria de Educação Profissional e Tecnológica do Ministério da Educação (2014), possibilita deduzir que a saúde não é considerada como uma das possíveis causa da evasão. O Documento visava criar um plano de ação composto por sete dimensões que abrangem o entendimento dos fenômenos da evasão e retenção e medidas para o seu combate, a formação de parcerias, o desenvolvimento da pesquisa e inovação, a inserção profissional dos estudantes, a distribuição de cargos e funções às instituições, a capacitação dos servidores e a avaliação de cursos de educação profissional e tecnológica, no entendimento de que com a expansão e a interiorização da Rede Federal de Educação Profissional, Científica e Tecnológica (Rede Federal) têm proporcionado, desde 2006, a ampliação física e a democratização da oferta de vagas ( $p$. 4), a necessidade para um olhar sobre a qualidade do ensino, o atendimento à diversidade, a permanência e o êxito dos estudantes no processo educativo com objetivo de fortalecer a ação educacional (BRASIL, 2014b).

No entanto, das ações e estudos não há menção do impacto do ascendente fenômeno do adoecimento nos escolares. O Documento Orientador sugere ainda que cada instituição da Rede Federal elabore e desenvolva um Plano Estratégico de Intervenção e Monitoramento para Superação da Evasão e Retenção. As metas e as ações desse plano deverão estar previstas no Plano de Desenvolvimento 
Institucional (PDI), e os resultados no relatório anual de gestão institucional (BRASIL, 2014b, p. 29). No PDI, já citado aqui, também não há o referido Plano Estratégico, tão pouco a inclusão do tema saúde (BRASIL, 2014b).

Depreende-se, pois, que a inclusão do tema faz-se necessária, não apenas para ampliar a discussão dentro da escola, mas também para tornar concretas e definidas as ações de saúde através de a uma política que seja adequada às singularidades dos sujeitos e à realidade de cada local.

\section{POR ONDE PODE COMEÇAR}

No inicio deste estudo foi explicitado o sentido e entendimento de saúde escolar. Em acréscimo, menciona-se que "a escola deve ser entendida como um espaço de relações, um espaço privilegiado para o desenvolvimento crítico e político, contribuindo na construção de valores pessoais, crenças, conceitos e maneiras de conhecer o mundo e interfere diretamente na produção social da saúde" (BRASIL, 2009, p. 10).

Para atingir a esta finalidade é preciso um conjunto de ações e medidas, podendo se dar através de simples ações e atividades, como também de projetos e planos mais complexos construídos coletivamente com o intuito de promover saúde e prevenir doenças. Por se tratar de um espaço de relações, as ações e planos terão maior efetividade principalmente se forem trabalhados de forma institucional e articulados de forma intersetorial (BRASIL, 2009).

No caso dos institutos, um dos canais institucionais que pode ser utilizado é o PPPI - Projeto Político Pedagógico Institucional, visto que este é um instrumento que permite a flexibilização em sua construção:

"é necessário que se afirme o caráter de reflexão contínua que este documento possui em seu cerne. Consequentemente será este um texto em permanente (re)construção, que, não obstante essa flexibilidade, será referência cotidiana para o fazer pedagógico desta instituição" (BRASIL, 2014a, p. 66).

Com isto, há a inclusão dos diversos setores e profissionais daquele ambiente, interstoriando as ações:

Promover a saúde envolve ações para criar qualidade de vida da coletividade, com ambientes que apoiem a saúde mental e permitam às pessoas adotar e manter estilos de vida saudáveis, sendo necessária a sua participação ativa, a partir de gestão compartilhada entre todos os indivíduos, os movimentos sociais, os trabalhadores e os gestores públicos e também privados, construindo uma rede baseada na corresponsabilização dos atores, conservando sua autonomia e a subjetividade (BRASIL, 2010 citado por NEGREIROS; SOUZA, 2017, p. 157).

Sobretudo por que:

A Promoção da Saúde Mental implica na intersetorialidade, de forma a acolher o indivíduo em sua integralidade, devendo ainda ser trabalhada ao longo do ciclo de vida, para garantir às crianças um início de vida saudável, prevenir transtornos mentais na fase adulta e velhice, assegurar qualidade de vida nas relações de cuidado e elaboração psíquica apropriadas na superação de possíveis agravos físicos através do acolhimento, vínculo, corresponsabilização e autonomia, visando atingir um cuidado integral (BRAGA et al 2015; JORGE et al 2011 citados por NEGREIROS; SOUZA, 2017, p 158). 
A saúde de fato é uma questão complexa, pois envolve pessoas, que em regra possuem um todo complexo ligado e articulado. Por isso resolver os problemas ligados à saúde requer parceria, cooperação e colaboração. Contudo, o cuidado com a saúde dos escolares não deve seguir um script pronto nem fórmula, é necessário considerar os sujeitos em sua complexidade e sua realidade concreta (PORTUGAL 2006 citado por BRASIL, 2009).

Também é preciso considerar alguns passos para construção de uma política de saúde: a definição dos objetivos ou problemas identificados; investigação do diagnóstico; e a definição das estratégias ou planos de ação a serem adotados (FLEURY; OUVERNEY, 2008).

Além desses passos, a política de saúde escolar deve seguir ainda outros elementos e etapas: a "seleção de atividades e ações, avaliação de custos/orçamento para o projeto - quando for o caso -, avaliação do projeto" (PORTUGAL 2006 citado por BRASIL, 2009). Pode-se também inserir algumas premissas e diretrizes que se tornam primordiais para a melhor condução das ações e resultado dos objetivos esperados, (CHIAVERINI, 2011 citado por BRASIL, 2013):

Ver o indivíduo de forma singular e seu todo integral e complexo, sem generalizar seu sofrimento/adoecimento;

A pessoa e suas multidimensões (sociais, econômicas, políticas, etc) como ponto de partida e não a doença/sofrimento;

Evitar uma postura de culpabilizar o aluno pelo sofrimento manifestado;

Exercer boa comunicação;

Exercitar a habilidade da empatia;

Lembrar-se de escutar o que o usuário precisa dizer; Acolher o usuário e suas queixas emocionais como legítimas; Oferecer suporte na medida certa; uma medida que não torne o usuário dependente e nem gere no profissional uma sobrecarga; Reconhecer os modelos de entendimento do usuário.

Outra iniciativa importante neste rol é a adesão aos direcionamentos do Programa de Saúde Escolar - PSE:

O PSE é uma política de saúde na escola que se propõe a articular e integrar permanentemente os setores saúde e educação com ações que buscam melhorar a qualidade de vida dos alunos de escolas de educação básica, tendo por base ações de prevenção, promoção e atenção à saúde (SÁ, 2020).

Por isso, segundo Sá (2020) é imperativo considerar:

[...] o papel do PSE como um importante espaço para a articulação das equipes de atenção básica com os profissionais de educação, proporcionando a sustentabilidade das ações valendo-se da conformação de redes de responsabilidade compartilhada sobre o território. As ações de promoção da saúde e prevenção de doenças e agravos realizadas no PSE visam a garantir oportunidade a todos os educandos de fazer escolhas mais saudáveis e de serem protagonistas do processo de produção da própria saúde (SÁ, 2020).

Em consonância à fala de Sá (2020), o protagonismo juvenil, por fim, é, outro aspecto que irá somar positivamente numa política de saúde escolar, além da necessidade de mudança na cultura organizacional. No modelo tradicional de 
promoção e prevenção da saúde escolar, o indivíduo deixa de ser visto em sua singularidade, uma vez que o objetivo maior é a cura da doença, o profissional de saúde estabelece uma relação vertical com o usuário, outorgando-se o direito de ditar normas de conduta acreditando que, assim fazendo, proporcionará ao usuário uma qualidade melhor de vida. Essa postura coloca a pessoa numa posição de inferioridade e de passividade, retirando dele não só a liberdade de escolha, como também a responsabilidade por seus atos (BRASIL, 2017, p. 36). Ademais,

\begin{abstract}
"na nova proposta de atenção integral, o objetivo é ampliar a possibilidade de atuação do profissional, tendo como preocupação não só a singularidade do sujeito, mas também a organização dos serviços. Com isso, transformase o espaço antes considerado como o "lugar, por excelência, do profissional" - um lugar de poder - em outro em que se busca uma interação maior dos profissionais com a população assistida" (BRASIL, 2017, p. 37)
\end{abstract}

A abertura para o protagonismo juvenil requer o oferecimento de informação, toda e qualquer informação necessária, assim como uma disponibilidade, por parte do profissional, para a escuta do adolescente. "A informação, num sentido amplo, possibilita ao jovem dispor de conhecimento que lhe permitirá tomar decisão quanto à sua conduta, em lugar de ser submetido a valores e normas que o impedem de exercer seu direito de escolha na administração de sua própria vida" (BRASIL, 2017, p. 38).

A autonomia nos cuidados com a saúde além de gerar autoconhecimento, emancipação e melhor cuidado com a saúde no geral, pode proporcionar ainda menos sobrecarga para os profissionais, gera senso de responsabilidade e estima pessoal (BRASIL, 2017). Em conclusão, a promoção e prevenção da saúde através de uma política de saúde escolar requerem monitoramento e avaliação para melhor condução dos resultados esperados:

"[...] o monitoramento representa o rol de esforços para o acompanhamento sistemático a respeito de algum dos aspectos de uma determinada intervenção, por meio de indicadores mensurados a partir da coleta continua de dados, a avaliação corresponde ao exercício de mensurar, compreender e julgar os efeitos de uma determinada intervenção, de maneira a subsidiar as escolhas da comunidade política no processo de tomada de decisão, seja ele na etapa de formulação ou implementação da intervenção avaliada" (SOUSA, 2018, p. 2).

De acordo com o exposto, estes procedimentos são cruciais para a efetividade de planos e políticas permanentes, pois visa acompanhar os objetivos e rever estratégias, ações e atividades sempre que se fizerem necessárias para melhor atender aos objetivos propostos.

\title{
CONSIDERAÇÕES FINAIS
}

A partir da discussão foi possível perceber a estreita vinculação entre os modos sociais e econômicos de viver à necessidade do educar através das escolas e como isto pode impactar negativamente na saúde e na vida dos indivíduos, principalmente para os jovens provenientes da classe trabalhadora que têm na escola pública um reflexo do sistema econômico e social, com as devidas consequências que isto pode gerar.

Esta histórica e cultural vinculação se mostrou ainda mais alarmante na contemporaneidade com as alterações no mercado de trabalho e nas relações de produção social, com novas exigências de adaptabilidade e sobrevivência, gerando 
grandes desafios para a conclusão do processo formativo saudável para os que buscam na própria escola uma transformação, se concretizando aí uma contradição.

Desse modo, no decorrer da abordagem questionamos se as escolas buscam cuidar dos seus jovens para que reduzam os efeitos das exigências da sociedade moderna e do percurso escolar neste cenário para a saúde, principalmente psíquica, e se é possível à escola atenuar esses impactos no processo formativo e consequentemente inserir profissionais integrais e minimamente saudáveis no mercado de trabalho e na sociedade.

Foi possível responder em parte a estas inquietações, com a percepção de que a escola em foco, os institutos, possui um fazer educacional que pode ser um fator agravante para a saúde dos escolares em decorrência de suas especificidades acadêmico-pedagógicas e a necessária adaptação que esses escolares precisam ter a esta dinâmica, sendo a proteção da saúde realizada de forma superficial.

Não há, com isto, o julgamento de que a escola seja a causadora do adoecimento e correlatos, mas que a sua relação com a sociedade, seu fazer educacional, a carga curricular no caso da modalidade de ensino da EPT, e em especial, a falta de políticas especificas para a saúde podem colaborar para agravos. Esta ausência vai de encontro às finalidades precípuas a que se destina a formação integral, missão do IFS. Ademais, pode contribuir para aumento da evasão e do tão temido fracasso escolar.

Sobre este ponto chama atenção que apesar de ampla pesquisa no campo educacional sobre permanência e evasão, seja através de pesquisa com abordagem conjunta dos temas ou como temas separados, a saúde escolar, como fator que impacta em ambos, é pouco explorada nesse sentido. Percebemos que há também uma carência de dados e estudos comprovados da ligação do adoecimento/sofrimento na trajetória escolar ao aumento da evasão/retenção, justamente talvez porque o tema não é considerado neste aspecto.

Respondendo ao segundo questionamento, se a escola pode atenuar os impactos das exigências da sociedade moderna no processo formativo, também foi possível identificar que sim, através da criação de uma política de saúde efetiva e permanente que envolva a todos os atores do espaço escolar, seguindo uma construção planejada e concreta.

Foi possível, sobretudo, a compreensão de que as instituições devem inserir as ações de saúde no processo pedagógico, considerando a contemporaneidade desafiadora para os jovens da classe trabalhadora que buscam na formação escolar seu desenvolvimento e transformação. Assim, proporciona um ambiente saudável, um fazer pedagógico também e necessariamente saudável, em prol de uma escola que busca a redução de vulnerabilidades sociais decorrentes do contexto socioeconômico vigente para promoção da cidadania e da saúde.

\section{REFERÊNCIAS}

ALMEIDA, M. D. B. de. Desafios para a Conclusão do Ensino Médio Integrado no IFG Uruaçu: O que Dizem os Alunos, Pais e Professores. 2018. Acesso Em: 07 de abr. de 2021. DOI 10.29327/15299.2-2. ISSN: 2595-8496.

ANTUNES, R. Os sentidos do trabalho: ensaio sobre a afirmação e a negação do trabalho. 5 edição. São Paulo, Boitempo, 2003.

ANTUNES, R.; PINTO, A. G. A fábrica da educação: da especialização taylorista à flexibilização toyotista. São Paulo: Cortez, 2017. 
ARAÚJO, A. C.; SILVA, C. N. N. da (orgs.). Ensino médio integrado no Brasil: fundamentos, práticas e desafios. Brasília: Ed. IFB, 2017.

BERTRAND, Y. Teorias Contemporâneas da Educação, Lisboa, Instituto Piaget, 2001.

BRASIL. Constituição da República Federativa do Brasil de 1988. Disponível em: <http://www.planalto.gov.br/ccivil_03/constituicao/constituicao.htm>. Acesso em 30 de março de 2020.

BRASIL. Ministério da Saúde. Secretaria de Atenção à Saúde. Departamento de Atenção Básica. Saúde na escola. Brasília: Ministério da Saúde, 2009. 96 p. (Cadernos de Atenção Básica; n. 24). ISBN 978-85-334-1644-4.

BRASIL. Ministério da Saúde. Secretaria de Atenção à Saúde. Departamento de Atenção Básica. Saúde Mental. Brasília: Ministério da Saúde, 2013. 176 p. (Cadernos de Atenção Básica; n. 34). ISBN 978-85-334-2019-9.

BRASIL. Ministério da Saúde. Secretaria de Atenção à Saúde. Departamento de Ações Programáticas e Estratégicas. Proteger e cuidar da saúde de adolescentes na atenção básica. Brasília: Ministério da Saúde, 2017. 234 p. ISBN 978-85-3342470-8. Acesso em 20 de abril de 2021.

BRASIL. Plano de Desenvolvimento Institucional (PDI) 2014-2019. Aracaju, Se: 2014a. Instituto Federal de Sergipe. Disponível em: http://www.ifs.edu.br/maiscomunicados/6199-plano-de-desenvolvimento-institucional-pdi-2014-2019. Acesso em 05 de abril de 2020.

BRASIL. Documento Orientador para a Superação da Evasão e Retenção na Rede Federal de Educação Profissional, Científica e Tecnológica - MECSETEC. Brasília, DF: 2014b. Disponível em: http://r1.ufrrj.br/ctur/wpcontent/uploads/2017/03/DocumentoOrientador-SETEC.pdf. Acesso em 05 de abril de 2020.

CHARLOT, B. Da relação com o saber às práticas educativas [livro eletrônico] / Bernard Charlot. -- 1. ed. -- São Paulo: Cortez, 2014. ISBN 978-85-249-2231-2.

FLEURY, S.; OUVERNEY, A.M.; Política de saúde: uma política social. In: Giovanella L, Escorel S, Lobato LVC, Noronha JC, Carvalho Al (org.). Políticas e sistema de saúde no Brasil. Rio de Janeiro: Fiocruz; 2008. P. 23-64.

GRANER, K. M.; CERQUEIRA, A. T. de A. R. Revisão integrativa: sofrimento psíquico em estudantes universitários e fatores associados. Ciência saúde coletiva [online]. 2019, vol.24, n.4, pp.1327-1346. ISSN 16784561. https://doi.org/10.1590/1413-81232018244.09692017.

HAN, B. Sociedade do cansaço / Byung-Chul Han; tradução de Enio Paulo Giachini. - Petrópolis, RJ: Vozes, 2015. 
HORTA, R.L; ANDERSEN, C. S; PINTO, R. O; Horta B. L.; OLIVEIRA, C. M.; et al. Promoção da saúde no ambiente escolar no Brasil. Revista Saúde Publica. 2017; 51:27. https://doi.org/10.1590/S1518-8787.2017051006709.

KUENZER, A. Z.; Sistema educacional e a formação de trabalhadores: a desqualificação do Ensino Médio Flexível. Ciência \& Saúde Coletiva [online]. 2020, v. 25 , n. 1, p. 57-66. ISSN 1678-4561. https://doi.org/10.1590/141381232020251.28982019. Acesso em: 01 de jun. de 2021.

MACHADO, F. C. DE A.; SILVA, J. V.; ALMEIDA, G. M. S. A. DE; FILGUEIRA, A. C. G.; MEDEIROS, I. DE B.; NASCIMENTO, T. A. R. DO. Construção Participativa de uma Política de Saúde para Institutos Federais. Revista Ciência Plural, v. 4, n. 2, p. 38-59, 2019.

MARTINS, J. F.; WINGERT, V. D. Na Relação Capitalismo-Educação, Quais as Concepções Educacionais Vigentes. 2017. Revista Gestão Universitária. Disponível em: http://gestaouniversitaria.com.br/artigos/na-relacao-capitalismoeducacao-quais-as-concepcoes-educacionais-vigentes\#. ISSN: 1984-3097. Acesso em: 02 de mai. 2021.

MOURA, D. H. Educação Básica e Educação Profissional e Tecnológica: Dualidade histórica e perspectivas de integração. Holos, Natal/RN, v. 2, p. 4-30, 2007. http://www2.ifrn.edu.br/ojs/index.php/HOLOS/article/view/11/110. Acesso em: 20 de mai. 2020.

NEGREIROS, F., SOUZA, M. P. R. de. Práticas em psicologia escolar: do ensino técnico ao superior. 2017. Teresina: EDUFPI, 2017. 4 v. 254p. ISBN: 978-85-5090117-6.

OMS - Organização Mundial de Saúde. Declaração de Alma-Ata: primeira conferência internacional sobre cuidados primários de saúde. Genebra, 1978. Disponível em: <https://doi.org/10.1590/S0104-12902015000200024>. ISSN 19840470.

PERUZZO, A.; CATTANI, B.; GUIMARÃES, E.; BOECHAT, L.; ARGIMON, I.; et al. Estresse e Vestibular como Desencadeadores de Somatizações em Adolescentes e Adultos Jovens. 2017. Psicologia Argumento, 26(55), 319-327. Disponível em: https://periodicos.pucpr.br/index.php/psicologiaargumento/article/view/20003. Acesso em: 02 de jun. de 2021.

RAMOS, M. N.; História e política da educação profissional. Curitiba: Instituto Federal do Paraná, 2014. (Coleção formação pedagógica; v. 5).

SÁ, M. R. C. de. Promoção da saúde e ações intersetoriais: foco no Programa Saúde na Escola. Cadernos de Saúde Pública, Rio de Janeiro, v. 36, n. 3, e00001620. 2020. Disponível em: http://cadernos.ensp.fiocruz.br/csp/artigo/1006/promocao-da-saude-e-acoesintersetoriais-foco-no-programa-saude-na-escola. Acesso em 04 de jun. de 2021. http://dx.doi.org/10.1590/0102-311X00001620. 
SILVA, M. V. O.; SILVA., L.M. P.; Quando O Sonho Vira Pesadelo: Uma Análise do Adoecimento E Sofrimento dos Discentes na Graduação. 2018. IV congresso em desenvolvimento social. Disponível em: http://congressods.com.br/anais_sexto/ARTIGOS_GT11/QUANDO\%200\%20SONH O\%20VIRA\%20PESADELO\%20UMA\%20ANALISE\%20DO\%20ADOECIMENTO\%2 0E\%20SOFRIMENTO\%20DOS\%20DISCENTES\%20NA\%20GRADUACAO.pdf. Acesso em 27 de mar de 2020.

SOUSA, A. N.; Monitoramento e avaliação na atenção básica no Brasil: a experiência recente e desafios para a sua consolidação. Saúde em Debate [online]. v. 42, n. spe, p. 289-301, 2018. ISSN 2358-2898. https://doi.org/10.1590/010311042018S119. Acesso em 03 de jun. de 2021.

SOUZA, S.R.; TEIXEIRA, I.; O adoecimento psíquico vivenciado na adolescência no período pré-vestibular. Humanidades e Inovações, São Paulo, p. 63 , v. 4, n. 2 , 2016. https://revista.unitins.br/index.php/humanidadeseinovacao/article/view/196. Acesso em 20 de jun. 2021.

VALADÂO, M. M. Saúde na escola: um campo em busca de espaço na agenda intersetorial. Tese (Doutorado em Serviços de Saúde Pública) - Faculdade de Saúde Pública, Universidade de São Paulo, São Paulo, 2004. doi:10.11606/T.6.2004.tde-12022007-152151. Acesso em: 05 de maio de 2021.

VARANI, A.; CAMPOS, C. M.; ROSSIN, E. A Formação Humana Integra a Educação Integral? $O$ que as Práticas Pedagógicas têm a nos dizer. Cadernos CEDES [online]. , v. 39, n. 108, p. 177-192. 2019. ISSN 1678-7110. https://doi.org/10.1590/CC0101-32622019218950. Acesso em 03 de jun. de 2021. 